\title{
LANDSLIDE MAPPING IN SWITZERLAND WITH ENVISAT ASAR
}

\author{
Urs Wegmüller ${ }^{1}$, Tazio Strozzi ${ }^{1}$, Reynald Delaloye ${ }^{2}$, and Hugo Raetzo ${ }^{3}$ \\ ${ }^{1}$ Gamma Remote Sensing, 3073 Gümligen, Switzerland \\ http://www.gamma-rs.ch, E-Mail: wegmuller@gamma-rs.ch \\ ${ }^{2}$ Université Fribourg, 1700 Fribourg, Switzerland \\ ${ }^{3}$ Bundesamt für Umwelt, 3003 Bern, Switzerland
}

\begin{abstract}
In the frame of the IGARSS 2012 special session on ENVISAT the landslide mapping activities in Switzerland using ENVISAT ASAR data are presented. Between 2005 and 2010 the building up of a well suited archive over the Swiss Alps was realized through programming of all IS2 mode data during the snow free period. In recent years DINSAR and PSI based landslide inventory and monitoring products started to play an important role in the updating of hazard maps.
\end{abstract}

Index Terms- DINSAR, PSI, landslide inventory, landslide monitoring

\section{INTRODUCTION}

Landslide is a natural hazard of special relevance in Alpine regions with a severe damage potential to human lives and infrastructure. An important tool in the risk management are hazard maps containing information on the location and characteristics of potential hazards, i.e. on areas potentially prone to natural hazards. In Switzerland regional hazard maps (Gefahrenhinweiskarten) at 1:25'000 scale are the responsibility of the regional authority (Canton). Local hazard maps (Gefahrenkarten) at 1: 5'000 are the responsibility of the local authority (Community). The landslide hazard is one of the hazards covered in these maps. The Federal Agency for the Environment (FOEN) has an important role as coordinator and regulator for many of the related activities. In several Cantons with alpine territory the hazard maps are currently being established. In this process satellite SAR interferometry is one of the information sources considered.

In this contribution the focus is on the use of ENVISAT ASAR data for landslide mapping in Switzerland.

\section{LOOKING BACK}

With the launch of ERS-1 in 1991 repeat-pass satellite SAR data suited for differential interferometry (DINSAR) became easily available. From its foundation in 1995 the Swiss Company Gamma Remote Sensing has been involved in the development of related processing techniques and applications.

Related specific activities on landslides in Switzerland started in 2000. Early on, we noted the potential of short baseline differential interferograms with adequate time intervals to map the motion of active landslides. Short baselines were preferred because of the very strong influence of the topography on the interferometric phase. A time interval is adequate if the displacement phase is between a significant fraction of a phase cycle and a few phase cycles. C-band ERS data [1-3] as well as L-band JERS data [4-5] were used. Funding from the ESA Projects (DUP Alps, DUE SLAM) supported this development in the first years. Considering their important responsibility concerning natural hazards we got the related sections of several Cantons with Alpine territory involved as users. Furthermore, we cooperated with geoscientists with specific experience on the landslide hazard. It turned out that the interpretation of the differential interferograms is not trivial due to their incomplete spatial coverage (gaps for low coherence areas), the special SAR geometry (gaps for layover and shadow regions), and the fact that only the lineof-sight component of the motion is observed. Based on these difficulties the start was not easy and the success finally achieved depended very much on the few partner geoscientists and users who rather saw the high potential of the techniques and not only its significant limitations.

Until 2005 a certain maturity was reached, in the meantime the DINSAR methodology was complemented by Persistent Scatterer Interferometry (PSI), permitting to increase the activities, partly within the ESA Project TERRAFIRMA (www.terrafirma.eu.com), partly funded by the Swiss Federal Agency for the Environment (FOEN). 


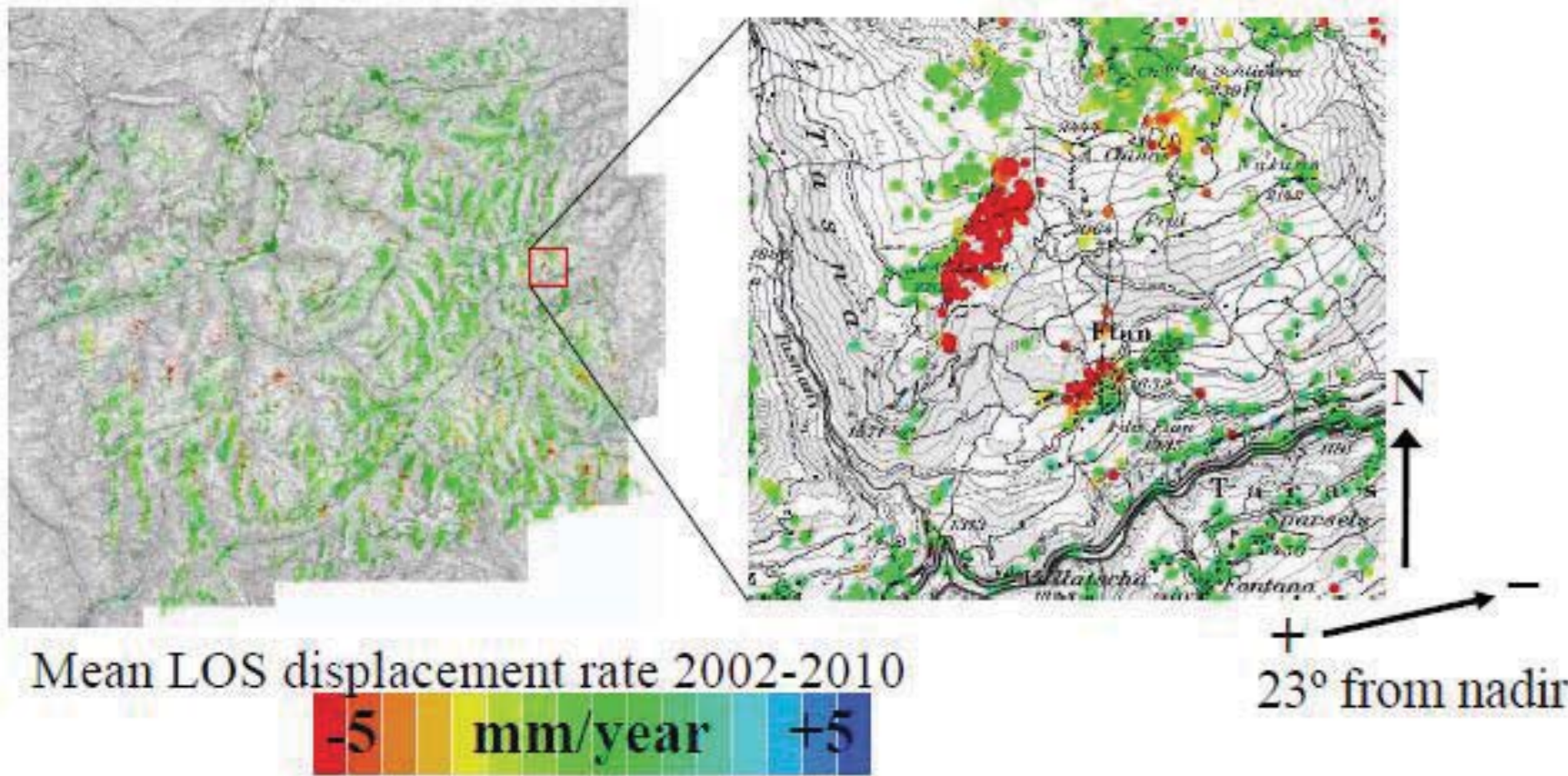

Figure 1 Average deformation rate over Canton Grison derived from ENVISAT ASAR data in ascending track 215. Full frame overview (left) and detailed view of small section around the village Ftan.

As the two main products the landslide inventory product and the landslide monitoring product were defined [6]. The inventory product consists of PSI based average displacement rates complemented typically by several well suited differential interferograms. The monitoring product is a more local product and includes PSI based deformation time series.

Up to about 2006 primarily ERS data were used. Then ENVISAT became important to have more up-to-date information.

\section{THE ROLE OF ENVISAT}

Between 1992 and 2000 ERS-1 and ERS-2 acquired significant stacks of repeat observations over the Swiss Alps. These stacks are well suited for both PSI and DINSAR. Apart from the 35-day intervals and multiples thereof the short 1-day interval of ERS-1/2 Tandem acquisitions is of interest to map very fast movements, as observed for example for rock glaciers. In 2000 ERS-1 failed and at the end of the year the attitude control of ERS-2 degraded because of failures of several gyroscopes, causing very significant yaw variations with Doppler Centroid deviations from the nominal value of several KHz. In 2002 ENVISAT ASAR was launched and there was great hope that the landslide application can be continued with it. This was not immediately the case though over the Swiss Alps. Probably because of the many operation modes of ENVISAT ASAR no consistent archives were built up. To resolve this we decided to program all the spring, summer, and fall acquisitions of all the ascending and descending tracks over the Swiss Alps in IS2 mode, resulting in an excellent archive for the period 2005 to 2010 with a few extra acquisitions before 2005. Considering both ascending and descending orbits is important because different geometries are preferred for different slope orientations. Ascending orbit data are used for slopes oriented to the East, descending orbit data for slopes oriented to the West.

In the meantime ENVISAT ASAR based landslide products were generated for large parts of the Swiss Alps. Landslide survey or inventory products are generated to recognize slope instabilities and average rates over large areas. Such inventory products include the average deformation rate estimated in a PSI analysis (see Figure 1) complemented by a number of high coherence short baseline differential interferograms (see Figure 2). For selected areas of particular interest more local monitoring products were generated to get more detailed information on the dynamics of the landslides.

\section{METHODOLOGIES USED}

\subsection{Differential interferometry (DINSAR)}

In DINSAR the interferometric phase is separated into different phase components. In the so-called 2-pass approach the topographic phase component is estimated based on an available digital elevation model and subtracted from the interferogram. The phase of the resulting differential interferogram includes the deformation phase as the "main signal" and the atmospheric phase, phase noise, residual topographic phase, and residual orbital phase as the main error terms. If no DEM is available multi-pass 


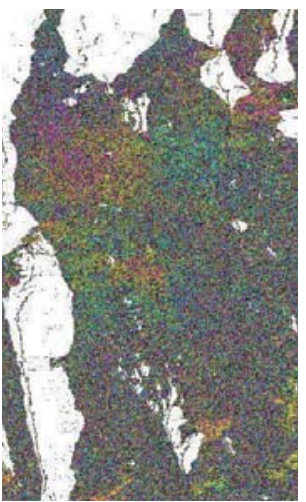

2005062120060815

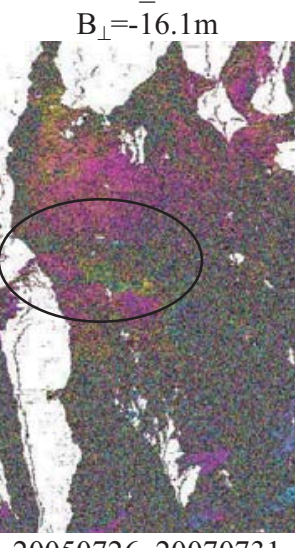

2005072620070731

$\mathrm{B}_{\perp}=13.9 \mathrm{~m}$
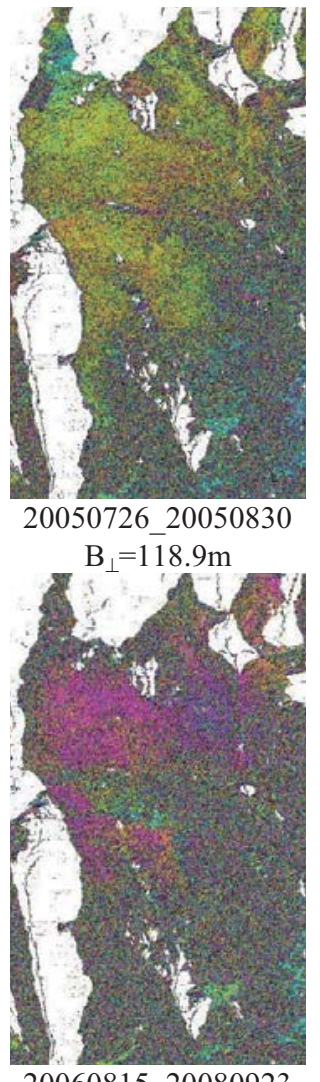

2006081520080923

$\mathrm{B}_{\perp}=-45.2 \mathrm{~m}$

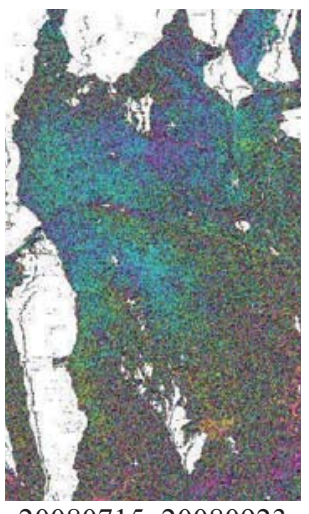

2008071520080923

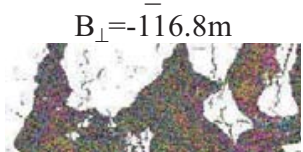

스.

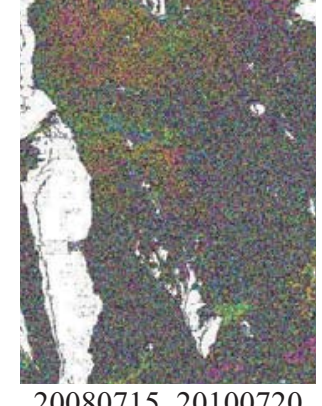

2008071520100720

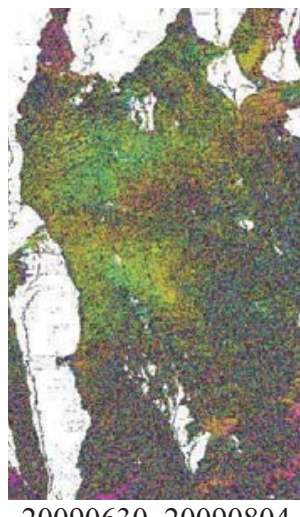

$20090630 \quad 20090804$
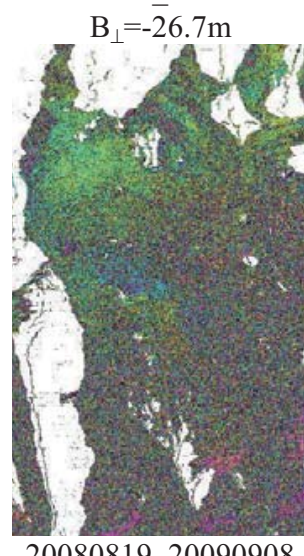

2008081920090908

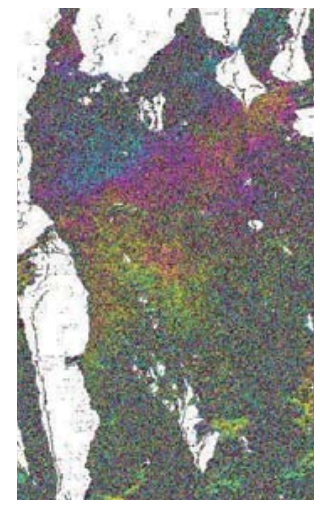

2010061520100824

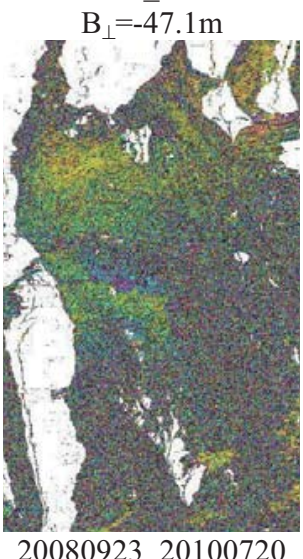

$\mathrm{B}_{\perp}=-28.2 \mathrm{~m}$

Figure 2 Section of differential interferograms over Flims. In the upper row pairs with time intervals between 35 days and 70 days are shown. The lower row shows pairs with time intervals of between 1 year and 2 years. Apart from the acquisition dates the perpendicular baseline of the pairs is indicated as this is relevant to judge if residual topographic phase may be relevant.

differential interferometry can be used to still separate the topography and deformation related components. In Alpine terrain we usually also consider a height dependent atmospheric path delay component, assuming a linear model between the topographic height and the related path delay phase correction.

Pairs acquired with different acquisition intervals are used to identify and quantify different deformation rates. Short intervals are better suited for fast deformations. Long intervals for slow deformations. Ideally, the movements cause differential interferometric phases between about $\pi$ and $9 \pi$. For smaller values the accuracy is too low considering possible atmospheric distortions and for larger values phase unwrapping is often not possible due to too high phase gradients. To confirm a deformation signal multiple consistent observations should be used to reasonably exclude atmospheric artifacts. Using ENVISAT ASAR data no very short repeat interval as the 1-day interval of ERS-1/2 Tandem pairs is available. With the 35 day interval $\mathrm{cm}$ to $\mathrm{dm}$ rates per month can be identified. Using pairs with an interval of the order of one to several years $\mathrm{cm}$ to $\mathrm{dm}$ rates per year can be identified. An example is shown in Figure 2 for a small area above Flims. The Non- zero displacement phase is consistently observed for the 5 pairs with intervals between one and two years but not for 35 and 70 day pairs. Slightly more than half a phase cycle is observed over two years which corresponds to a line-of-sight displacement rate of about $8-10 \mathrm{~mm} /$ year.

\subsection{Persistent Scatterer Interferometry (PSI)}

In PSI the temporal and spatial characteristics of interferometric signatures collected from point targets are exploited to accurately map surface deformation histories, terrain heights, and relative atmospheric path delays.

The phase model used is identical to conventional differential interferometry. To use targets with point like scatter characteristics, only, has the advantage that there is much less geometric decorrelation for these targets. This permits phase interpretation even for large baselines above the critical one. Consequently, more image pairs may be included in the analysis improving the temporal sampling. Another important advantages is the potential to find scatterers in low-coherence areas permitting filling spatial gaps in the deformation maps. The point-like scatterers very often correspond to infrastructure as buildings, or other temporally rather stable targets as rocks [7]. Due to their 
specific nature, targets with a point like scattering characteristics very often maintain coherence over long time periods.

Over the Swiss Alps we only consider data acquired during the snow free period. The coverage achieved at higher elevations clearly depends on the exact period considered. In Alpine terrain we usually also consider a height dependent atmospheric path delay which results in more accurate results and helps in solving the phase unwrapping. An example of a result over the Canton Grison is shown in Figure 1.

In the case of faster and non-uniform deformation we usually work initially with a multi-reference stack. In this stack shorter intervals, but including all baselines, are considered.

\section{BEYOND ENVISAT}

To continue the landslide mapping and monitoring activities we look forward to Sentinel-1. Getting full spatial coverage with more frequent repeat observations, i.e. 12 days with one and later on 6 days with 2 satellites, is very attractive for the landslide application. With shorter repeat intervals faster movements can be mapped and the spatial coverage will also improve. It is very important though to have this for both ascending and descending orbits. As demonstrated by ENVISAT having a large consistent archive is of very high value and particularly important for the monitoring of slow $\mathrm{mm} /$ year creeping rates. Using high resolution data (TerraSAR-X, Cosmo-Skymed) can complement this and is able to provide more detailed information for local fast phenomena, but it cannot really provide a global consistent archive, unless several sensors are operated in a strategic manner as done now for Cosmo-Skymed over Italy to achieve a complete archive of interferometric data with 16 day intervals.

Since several years the satellite SAR measurements over landslides are also more and more complemented by terrestrial interferometric measurements [8-9]. In particular in the case of faster movements and a more immediate hazard potential the possibility to more freely select the instrument location and repeat interval is an important advantage over the space-borne measurements.

\section{CONCLUSIONS}

For Switzerland landslide hazard mapping is an important task. PSI and DINSAR using the rich ENVISAT archive ensured by systematically programming all relevant 20052010 acquisitions has contributed significantly to this task and is currently being used as part of the ongoing generation of hazard maps as well as for a wide range of research studies. Over the lifetime of ENVISAT the application developed from a feasibility and demonstration activity to an operational service and relevant research tool [10-12].

\section{ACKNOWLEDGEMENTS}

ESA is acknowledged for proving ERS and ENVISAT data. The ESA Projects DUP ALPS, SLAM, and TERRAFIRMA, the Federal Agency for the Environment and the EC FP7 Project DORIS are acknowledged for their funding support.

\section{REFERENCES}

[1] Strozzi T., U. Wegmüller, C. Werner, and A. Wiesmann, Alpine landslide periodical survey, Proc. IGARSS 2002, Toronto, Canada, pp. 3629-3631, 24-28 June 2002.

[2] Strozzi T., A. Kääb and R. Frauenfelder, Detecting and quantifying mountain permafrost creep from in situ inventory, space-borne radar interferometry and airborne digital photogrammetry, Int. J. Remote Sensing, Vol. 25, No. 15, doi: 10.1080/01431160420001923302004.

[3] Delaloye R., C. Lambiel, R. Lugon, H. Raetzo and T. Strozzi, Typical ERS InSAR signature of slope movements in a periglacial mountain environment (Swiss Alps), Procs Envisat Symp., Montreux, Switzerland, 23-27 April 2007.

[4] Strozzi T., A. Kääb, R. Frauenfelder, and U. Wegmüller, "Detection and monitoring of unstable high-mountain slopes with L-band SAR interferometry", Proc. IGARSS 2003, Toulouse, France, 21-25 July 2003.

[5] Strozzi T., P. Farina, A. Corsini, C. Ambrosi, M. Thüring, J. Zilger, A. Wiesmann, U. Wegmüller and C. Werner, Survey and monitoring of landslide displacements by means of L-band satellite SAR interferometry, Landslides, Vol. 2, No. 3, pp. 193 - 201, doi: 10.1007/s10346-005-0003-2, 2005.

[6] Farina, P., Colombo, D., Fumagalli, A., Marks, F., Moretti, S.: Permanent Scatterers for landslide investigations: outcomes from the ESA-SLAM project. Eng. Geology 88: 200-217, 2006.

[7] Raetzo H., U. Wegmüller, T. Strozzi, F. Marks and P. Farina, Monitoring of Lumnez landslide with ERS and ENVISAT SAR data, Procs Envisat Symp., Montreux, Switzerland, 23-27 Apr. 2007.

[8] Wiesmann A., C. Werner, T. Strozzi, and U. Wegmüller, "Measuring deformation and topography with a portable Radar interferometer", Procs. IAG - FIG Symposium Lisbon, Portugal, 12 - 15 May 2008.

[9] Werner C., A. Wiesmann, T. Strozzi, A. Kos, and U. Wegmüller, "The GPRI Multi-mode Differential Interferometric Radar for Ground-based Observations", Procs. EUSAR 2012 Conf., 24-26. Apr. 2012.

[10] Delaloye R., T. Strozzi, C. Lambiel, C. Barboux, S. Mari, A. Stocker, F. Techel and H. Raetzo, The contribution of InSAR data to the early detection of potentially hazardous active rock glaciers in mountain areas, Procs ESA Living Planet Symp., Bergen, Norway, 28 June - 2 July 2010.

[11] Strozzi, T., R. Delaloye, A. Kääb, C. Ambrosi, E. Perruchoud and U. Wegmüller, Combined observations of rock mass movements using satellite SAR interferometry, differential GPS, airborne digital photogrammetry, and airborne photography interpretation, Journal of Geophysical Research, 115, F01014, doi:10.1029/2009JF001311, 2010.

[12] Ambrosi C. and T. Strozzi, Studio di fenomeni franosi in Ticino: fotointerpretazione e analisi delle deformazioni con interferometria radar da satellite, Bollettino della Società ticinese di Scienze naturali, No. 96, ISSN 079-1254, 2008. 